\title{
A Study of Awareness about Breast Cancer and Breast Self-Examination in Nursing Students
}

Kale Kalpana M, Aswar Nandkeshav R

Associate Professor, Department of Community Medicine, Government Medical College, Miraj Maharashtra, India

DOI: $10.36347 /$ sjams.2020.v08i09.009

| Received: 16.08.2020 | Accepted: 24.08.2020 | Published: 12.09.2020

*Corresponding author: Dr. Aswar Nandkeshav R

Abstract

Original Research Article

Introduction: Breast cancer is the leading cause of cancer death worldwide which makes it an important health issue in women. Nurses being the front-line health care workers can play an important role in imparting education about BSE in women as early detection is essential to breast cancer survival. Hence the present study was undertaken with an objective to assess the knowledge and practice of nursing students regarding breast cancer and BSE which will help to fulfil the gap in knowledge, if there any, by imparting BSE training to them. Material and methods: Study design: descriptive, cross-sectional workplace-based study. Study place: all six nursing schools in Akola city. Period of study: June to July 2018. Study subjects: All 180, $2^{\text {nd }}$ and $3^{\text {rd }}$ year female nursing students of all six nursing schools in a city. Data collection: Pretested semi structure questionnaire was used to collect information about personal characteristics of nurses, about causes, risk factors, screening methods and treatment available and knowledge about breast selfexamination. Ethical approval: Obtained from Institutional Ethics Committee and also permission was obtained from the principals of the concerned nursing schools. Results: out of 180 nursing students. 167 participated in the study. All participants have heard about breast cancer. Approximately $87.4 \%, 82.6 \%$ and $82.6 \%$ participants knew about various risk factors, various screening methods and different methods of treatment respectively. BSE was known to only $57.5 \%$ participants. Only $6.6 \%$ knew about proper method of BSE while only $17.4 \%$ knew about frequency of BSE. Only $5.3 \%$ practiced BSE. Conclusion: Though the knowledge of respondents about breast cancer is adequate, it requires reinforcing about the subject throughout their study. Their knowledge about BSE is very poor. Nurses should adopt such preventive screening procedure and act as role models for the patients and for the community.

Keywords: Breast cancer, Breast self-examination (BSE), lump, nursing students.

Copyright @ 2020: This is an open-access article distributed under the terms of the Creative Commons Attribution license which permits unrestricted use, distribution, and reproduction in any medium for non-commercial use (NonCommercial, or CC-BY-NC) provided the original author and source are credited.

\section{INTRODUCTION}

Breast cancer is the second most common cancer in the world and the most frequent cancer among women with an estimated 1.67 million new cancer cases diagnosed in 2012 [1]. Globally, over one million breast cancer cases are diagnosed annually [1]. This amounts to a total 411,000 deaths from breast cancer accounting for $14 \%$ of female cancer deaths worldwide [2, 3]. According to the World Health Organization (WHO), its incidence is expected to increase by $50 \%$ by 2020 [4]. Though the incidence of breast cancer has increased globally over the last several decades $[5,6]$, the greatest increase has been found to occur in the Asian countries [7]. The incidence varies between countries and regions. The developed countries account for almost $50 \%$ of breast cancers diagnosed worldwide [8]. It is estimated that about half $(60 \%)$ of breast cancer deaths occur in economically developing countries [3,9]. The lowest breast cancer incidence is reported from Far Eastern and South East Asian countries [10,11] and it is expected that in coming decades, these countries would account for majority of new breast cancer patients diagnosed globally.

In India, over 100000 new breast cancer patients are estimated to be diagnosed annually $[11,12]$. As per the ICMR-PBCR data breast cancer is the commonest cancer among women in urban area while it is second most common cancer in rural area after cancer of uterine cervix [13]. The age standardized incidence range from 6.2 to 39.5 per 100000 Indian women [13]. More than two-third of the patients are already in an advanced and incurable stage at the time of diagnosis [14]. In early stages, breast cancer is less aggressive with low incidence of metastasis and is potentially curable. Since the prognosis of this disease is influenced primarily by the stage at which intervention is introduced, secondary prevention (early detection) is the mainstay [15]. It has been documented that $85 \%$ of localized breast cancer cases have 5 year survival rate. 
But it drops to $56 \%$ for the regional disease and $18 \%$ to distant metastasis [16]. According to World Health Organization early detection of breast cancer is the cornerstone to improve the breast cancer outcome and survival [2] Hence Early detection through breast selfexamination (BSE) plays an important role in decreasing the morbidity and mortality rates [17]. In a resource- limited community, an important method of early detection is breast self-examination. It is relatively simple, convenient, affordable, noninvasive and less painful adjuvant screening method of early detection of breast cancer recommended for women [18]. There is evidence that women who correctly practice BSE monthly are more likely to detect a lump in the early stage of its development, and early diagnosis has been reported to influence early treatment to yield a better survival rate [19]. BSE does not require any specialized personnel or equipment; rather it is painless and inexpensive self- care action that can be done at home in about ten minutes [20]. However it has been documented that all the women who are advised about BSE by health care professional demonstrated greater knowledge and confidence and are more likely to practice this procedure routinely than those who become aware from other sources [21-27].

Nurses being the front line health care workers are in an excellent position to make use of many opportunities to encourage the women to be breast aware. They can play an important role in imparting education about BSE in women. But before they start educating the women they themselves need to be knowledgeable and confident regarding the BSE. Hence the present study was undertaken with an objective to assess the knowledge and practice of nursing students regarding BSE which will help to fulfil the gap in knowledge, if there any, by including it in their curriculum.

\section{Material And Methods}

A cross sectional study was conducted between June and July 2018 to study awareness about breast cancer and breast self-examination in nursing students. There are six nursing schools in Akola city. All 180 female nursing students of $2^{\text {nd }}$ and $3^{\text {rd }}$ year of these schools constituted the study population. Purpose of the study was explained to the participants before the start of study. All participants were assured of anonymity and confidentiality of responses and verbal consent was obtained from them. Pretested semi structure questionnaire was used to collect information about personal characteristics of nurses, about causes, risk factors, screening methods, treatment available and knowledge about breast self-examination. Ethical approval was obtained from Institutional Ethics Committee. Permission for conduct of study was also obtained from the principals of the concerned nursing schools before start of study. Out of 180 female nursing students, 13 students were absent at the time of study. Hence information was collected from 167 female nursing students by using self-administered questionnaire. The obtained data was analyzed by using Epi Info software.

\section{RESULTS}

Table-1: Personal characteristics of the study subjects $(n=167)$

\begin{tabular}{|l|l|c|c|}
\hline \multicolumn{2}{|c|}{ Parameters } & No. & $\%$ \\
\hline \multirow{2}{*}{ Age } & $18-20$ years & 124 & 74.2 \\
\cline { 2 - 4 } & Above 20 years & 43 & 25.7 \\
\hline \multirow{2}{*}{ Academic year } & Second year & 82 & 49.1 \\
\cline { 2 - 4 } & Third year & 85 & 50.9 \\
\hline \multirow{2}{*}{ Marital status } & Urban & 109 & 65.3 \\
\cline { 2 - 4 } & Rural & 58 & 34.7 \\
\hline Family history of breast cancer & Yes & 23 & 13.8 \\
\hline Personal history of breast lump & Yes & 144 & 86.2 \\
\cline { 2 - 4 } & Unmarried & 05 & 03.0 \\
\hline
\end{tabular}

Table 1: Mean age of the respondents was 21.1 \pm 2.3 SE. $124(74.2 \%)$ respondents were below 20 years of age. 109 (65.3\%0 were from urban area. Only
$23(13.8 \%)$ were married. $5(3.0 \%)$ respondents gave family history of breast cancer. $14(8.4 \%)$ respondents had personal history of breast lump. 
Table-2: Knowledge about risk factors for breast cancer

\begin{tabular}{|l|c|c|}
\hline Risk factors for breast cancer & No of respondents & Percentage \\
\hline Family history of breast cancer & 114 & 68.3 \\
\hline Early menarche & 33 & 19.8 \\
\hline Late menopause (after 55 years) & 134 & 80.2 \\
\hline Radiation exposure & 56 & 33.5 \\
\hline Prolonged use of oral pills & 56 & 33.5 \\
\hline Obesity & 76 & 45.5 \\
\hline Nulliparity & 115 & 68.9 \\
\hline Not breast feeding & 45 & 26.9 \\
\hline Hormone therapy for menopause & 54 & 32.3 \\
\hline Smoking/alcoholism & 56 & 33.5 \\
\hline
\end{tabular}

Table 2: All 167 respondents have heard about breast cancer. Majority of the respondents i.e. $87.4 \%$ knew about various risk factors for breast cancer, but the knowledge about early menarche, oral pills consumption for prolonged period, not breast feeding, and hormonal therapy for menopause as a risk factors were known to very few respondents i.e. to $19.8 \%$, $33.5 \%, 26.9 \%$ and $32.3 \%$ respectively. Only $33.5 \%$ nurses knew about smoking, alcoholism and radiation exposure as risk factors for breast cancer.

Table-3: Knowledge about warning signs, early detection measures and Treatment of breast cancer

\begin{tabular}{|c|c|c|c|}
\hline \multicolumn{2}{|l|}{ Items } & No. & Percentage \\
\hline \multicolumn{2}{|c|}{ Breast cancer is a public health problem } & 113 & 67.7 \\
\hline \multicolumn{2}{|c|}{ Can be detected in early stage by screening test } & 138 & 82.6 \\
\hline \multicolumn{2}{|c|}{ Early detection increases chances of survival } & 108 & 64.7 \\
\hline \multirow{7}{*}{$\begin{array}{l}\text { Warning signs of } \\
\text { breast cancer }\end{array}$} & Breast lump & 120 & 71.8 \\
\hline & Discharge through nipple & 114 & 68.3 \\
\hline & Pain in breast & 117 & 70.0 \\
\hline & Retraction of nipple & 103 & 61.8 \\
\hline & Change in shape and size of breast & 112 & 67.1 \\
\hline & Ulcer /swelling over breast & 110 & 65.9 \\
\hline & Discoloration over breast & 104 & 62.8 \\
\hline \multirow{4}{*}{$\begin{array}{l}\text { Screening \& } \\
\text { diagnostic methods }\end{array}$} & BSE & 96 & 57.5 \\
\hline & Mammography & 135 & 80.8 \\
\hline & FNAC / biopsy & 120 & 71.8 \\
\hline & Breast USG & 106 & 63.5 \\
\hline \multirow{4}{*}{$\begin{array}{l}\text { Treatment of breast } \\
\text { cancer }\end{array}$} & Surgery & 138 & 82.6 \\
\hline & Chemotherapy & 128 & 76.6 \\
\hline & Radiation/radiotherapy & 131 & 78.4 \\
\hline & Combination of above & 64 & 38.3 \\
\hline
\end{tabular}

Table 3: $67.7 \%$ respondents considered breast cancer as a public health problem, $82.6 \%$ opined that it can be detected in early stage by screening test. $64.7 \%$ said that early detection can improve the chances of survival. Various warning signs of breast cancer were known to more than $70 \%$ respondents. More than $80 \%$ respondents knew about one or other screening and diagnostic methods of breast cancer. Mammography,
FNAC/ biopsy, Breast USG as screening methods were known to $80.8 \%, 71.8 \%$ and $63.5 \%$ respectively. But only $57.5 \%$ respondents knew about Breast selfexamination (BSE) as a screening test for early detection of breast cancer. Various modalities of treatment i.e. surgery, chemotherapy, radiotherapy or combination of these were known to $82.6 \%, 76.6 \%$, $78.4 \%$ and $38.3 \%$ respectively.

Table-4: Awareness of participants about breast BSE

\begin{tabular}{|l|l|l|}
\hline Questions & No. & Percentage \\
\hline Heard of BSE & 127 & 76.0 \\
\hline BSE help in early diagnosis of breast cancer & 96 & 57.5 \\
\hline BSE is easy procedure which can be done at home & 48 & 28.7 \\
\hline BSE is conducted starting from age 18 years or older & 33 & 19.8 \\
\hline BSE should be performed monthly & 29 & 17.4 \\
\hline BSE should be performed at the end of menstrual period & 24 & 14.4 \\
\hline All stages of BSE knows & 11 & 06.6 \\
\hline
\end{tabular}


Table 4: Though $76.0 \%$ respondents heard about BSE, only $57.5 \%$ knew importance of BSE in early diagnosis of breast cancer and $28.7 \%$ said that it is an easy procedure that can be done even at home. Small number of respondents knew about starting age for BSE $(19.8 \%)$, frequency of doing BSE (i.e. monthly) $(17.4 \%)$, and time of doing BSE i.e. after the end of menstrual period (14.4\%). Only $6.6 \%$ respondents knew about all stages of BSE.

In the present study only $9(5.3 \%)$ respondents practice BSE regularly. Reasons of non-practicing BSE in 158 respondents were- not heard about BSE 40 (23.9\%), don't know the procedure of BSE 31 (18.7\%), do not have symptoms $47(28.1 \%)$, do not find time to do BSE 21(12.6\%), BSE is embarrassing $16(9.6 \%)$ and scared of being diagnosed for breast $3(1.8 \%)$

\section{DISCUSSION}

Breast cancer is one of the common cancers among women in the world and is a leading cause of mortality in them [5, 28-30]. It is the most common malignancy amongst Indian women after cervical cancer. It is estimated that one out of seven women either has or will develop breast cancer in her life time [31].

Nurses who are involved in direct patient care have a better opportunity to partake in patient assessment, management of symptoms, patient education and counselling, and also give supportive care. Awareness among nurses about various aspects of breast cancer and breast self-examination (BSE), are important, as they can identify the high risk women, and guide them appropriately.

In the present study, all 167 respondents have heard about breast cancer. $67.7 \%$ respondents considered breast cancer as a public health problem. Majority of the respondents knew about various risk factors for breast cancer, but their knowledge about early menarche, oral pills consumption for prolonged period, not breast feeding, and hormonal therapy for menopause as risk factors is poor as is the case in other developing countries [32-34].

Knowledge about established risk factors i.e. radiation exposure (33.5\%), obesity (45.5\%) and smoking /alcohol consumption (33.5\%) is also insufficient in them as contrast to the study done earlier [35].

Various warning signs of breast cancer were known to more than $70 \%$ respondents. $82.6 \%$ opined that it can be detected in early stage by screening test. $64.7 \%$ said that early detection can improve the chances of survival. More than $80 \%$ respondents knew about one or other screening and diagnostic methods of breast cancer. In contrast to this, Oluwole [36] in his study found poor knowledge about different methods of screening of breast cancer in the health care workers. In our study only $57.5 \%$ respondents knew about breast self-examination (BSE) as a screening test for early detection of breast cancer. Various modalities of treatment i.e. surgery, chemotherapy, radiotherapy or combination of these were known to $82.6 \%, 76.6 \%$, $78.4 \%$ and $38.3 \%$ respectively.

Our study revealed that very few participants have knowledge about the ease of BSE, starting age for BSE, frequency of doing BSE (i.e. monthly) and time of doing BSE i.e. after the end of menstrual period. Only $6.6 \%$ respondents knew about all stages of BSE. These findings are agreeing with the study done among Jordanian nurses [37, 38].

In the present study only $9(5.3 \%)$ respondents practice BSE regularly. This is due to limited knowledge about breast cancer and methods of early detection. While the study done by Al-Naggar et al. [39] reported that $55 \%$ of the respondents who had performed BSE before, only $28.5 \%$ of them practiced BSE once a month. Many other studies also reported that, $23 \%$ to $48 \%$ nurses practiced BSE regularly [4042].

In our study, 158 respondents do not practice BSE because of unaware about it and its procedure or because of reluctant to do BSE due to not having any symptoms or feeling embarrassing about it and having fear about its diagnosis in them. Sukhpal also reported that Majority of the students reported the reason for not doing BSE as 'do not get time'. The other reasons reported were 'not interested', 'do not consider it important' and 'feel embarrassed' [43].

In fact the students at this age usually have different priorities and do not discriminate ability to correlate the seriousness of the disease with BSE practice. This has been supported by many other studies in which the various reasons reported are 'forgetting', 'lack of confidence', 'fear of finding a lump', 'embarrassment', 'too busy' and thinking 'it is not necessary' [44-46].

\section{Conclusion}

Though the knowledge of respondents about breast cancer is adequate, it requires reinforcing about the subject throughout their study. It is also found from the present study that their knowledge about BSE is insufficient. BSE remains an important tool for the early diagnosis of breast cancer in our environment due to lack of facilities and screening program. Nurses being close in contact with the patients need to be properly educated to efficiently carry out this procedure. BSE and breast cancer education programmes should be integrated into the curriculum of nursing and as part of continuing nursing education (CNE) program. Nurses should adopt such preventive screening procedure and 
act as role models for the patients and for the community.

\section{REFERENCES}

1. Ferlay J, Soerjomataram I, Dikshit R, Eser S, Mathers C, Rebelo M, Parkin DM, Forman D, Bray F. Cancer incidence and mortality worldwide: sources, methods and major patterns in GLOBOCAN 2012. International journal of cancer. 2015 Mar 1;136(5):E359-86.

2. World Health Organization. Breast Cancer: Prevention and Control. Available from: http://www.who.int/cancer/detection/breastcancer/e $\mathrm{n} /$. [Last accessed on $2020 \mathrm{Jul}$ 01].

3. World Health Organization. Cancer Control: Knowledge Into Action: WHO Guide for Effective Programmes. World Health Organization; 2007.

4. American Cancer Society. Breast Cancer Facts \& Figure Atlanta: American Cancer Society. 20172018.

5. Hortobagyi GN, de la Garza Salazar J, Pritchard K, Amadori D, Haidinger R, Hudis CA, Khaled H, Liu MC, Martin M, Namer M, O'Shaughnessy JA. The global breast cancer burden: variations in epidemiology and survival. Clinical breast cancer. 2005 Dec 1;6(5):391-401.

6. Anderson BO, Jakesz R. Breast cancer issues in developing countries: An overview of the breast health global initiative. World J Surg. 2008; 32:2579-85

7. Green M, Raina V. Epidemiology, screening and diagnosis of breast cancer in the Asia-Pacific region: current perspectives and important considerations. Asia- Pacific Journal of Clinical Oncology. 2008 Dec;4:S5-13.

8. Parkin DM. Global cancer statistics in the year 2000. Lancet Oncol. 2001;2:533

9. Bodapati SL, Babu GR. Oncologist perspectives on breast cancer screening in India- results from a qualitative study in Andhra Pradesh. Asian Pac J Cancer Prev. 2013;14:5817-23.

10. National Cancer Registry Program: Ten year consolidated report of the Hospital Based Cancer Registries, 1984-1993, an assessment of the burden and care of cancer patients. Indian Council of Medical Research, New Delhi, 2001

11. Agarwal G, Pradeep PV, Aggarwal V, Yip CH, Cheung PS. Spectrum of breast cancer in Asian women. WorldJ Surg. 2007;31:1031-40

12. Nandakumar A, Anantha N, Venugopal TC, Sankaranarayanan R, Thimmasetty K, Dhar M. Survival in breast cancer: A population based study in Bangalore, India. Int J Cancer. 1995; 60:593-6

13. National Cancer Registry Program: Consolidated report of the population based cancer registries 1990-1996. Indian Council of Medical Research, New Delhi; 2001

14. Park K, Park K. Epidemiology of communicable diseases. Textbook of Preventive and Social Medicine. Banarsidas Bhanot. 2011; 21:244-50.
15. Moorison C. Determining crucial correlates of BSE in older women with low income. Oncology Nursing Forum. 1996; 23:83-92.

16. American Cancer Society. Cancer facts and figures. New York: 1993.

17. Somdatta P, Baridalyne N. Awareness of breast cancer in women of an urban resettlement colony. Indian J Cancer. 2008; 45:149-53.

18. Demirkiran F, Balkaya NA, Memis S, Turk G, Ozvurmaz S, Tuncyurek P. How do nurses and teachers perform breast self-examination: Are they reliable sources of information? BMC Public Health. 2007;7:96

19. Ertem G, Kocer A. breast self-examination among nurses and midwives in Odemis health district in Turkey. Indian J Cancer. 2009; 46: 208-13

20. Persson K. Breast self-examination: An analysis of self-reported practice. Journal of Advanced Nursing. 1997; 25: 886-892.

21. Bhakta P. Asian women's attitutes to breast selfexamination. Nursing Times. 1995: 91(8): 44-47

22. Patistea E. Breast self-examination: Knowledge and behaviour of Greek female health care professionals working in primary health care centers. Cancer Nursing. 1992; 15 (6): 415-42

23. Yarbro $\mathrm{CH}$. International nursing and breast cancer. Breast J. 2003; 9(Suppl 2): S98-S100.

24. Abu-Salem OA, Hassan MA. Breast selfexamination among female nurses in Jordan. Shiraz E Med J. 2007; 8(2): 51-57.

25. Hacihasanoğlu R, Gözüm S. The effect of training on the knowledge levels and beliefs regarding breast self-examination on women attending a public education centre. Eur J Oncol Nurs. 2008; 12(1): 58-64.

26. Lu ZY. Effectiveness of breast self-examination nursing interventions for Taiwanese community target groups. J Adv Nurs. 2001; 34(2): 163-170.

27. Mahloch J, Taylor V, Taplin S, Urban N. A breast cancer screening educational intervention targeting medical office staff. Health Educ Res. 1993; 8(4): 567-579.

28. Althuis MD, Dozier JM, Anderson WF, Devesa SS, Brinton LA. Global trends in breast cancer incidence and mortality 1973-1997. Int J Epidemiol. 2005; 34:405-12.

29. Jemal A, Bray F, Center MM, Ferlay J, Ward E, Forman D. Global cancer statistics. CA Cancer J Clin. 2011; 61:69-90.

30. Groot MT, Baltussen R, Uyl- de Groot CA, Anderson BO, Hortobágyi GN. Costs and health effects of breast cancer interventions in epidemiologically different regions of Africa, North America, and Asia. The Breast Journal. 2006 Jan;12:S81-90.

31. Cancer Registry Abstract, Newsletters. National Cancer Registry Project, India; 2001.

32. Taranikanti M, Panda S, Dash AK, Yasmeen N, Siddique ARO, Behara J. Knowledge of nurses about breast cancer risk factors, general awareness 
and screening procedures in South India. Int J Med Sci Public Health. 2014; 3:1372-1375.

33. Haji-Mahmoodi M, Montazeri A, Jarvandi S, Ebrahimi M, Haghighat S, Harirchi I. Breast selfexamination: knowledge, attitudes and practices among female health care workers in Tehran, Iran. Breast J. 2002; 8:222 - 5 .

34. Ghanem S, Glaoui M, Elkhoyaali S, Mesmoudi M, Boutayeb S, Errihani H. Knowledge of risk factors, beliefs and practices of female healthcare professionals towards breast cancer, Morocco. Pan Afr Med J. 2011; 10:21.

35. Yousuf SA, Al Amoudi SM, Nicolas W, Banjar HE, Salem SM. Do Saudi Nurses in Primary Health Care Centres have Breast Cancer Knowledge to Promote Breast Cancer Awareness? Asian Pac J Cancer Prev. 2012; 13:4459-64.

36. Oluwole O.C. Awareness, knowledge and practice of breast -Self Examination amongst Female Health Workers in A Nigerian Community, Sudan. JMS. 2008;3(2), 99-104.

37. Alkasawneh I.M., Knowledge and practice of breast cancer screening among Jordanian nurses, Oncol Nurs Forum. 2007; 34(6):1211-17.

38. Sahar M. Yakout, Abeer M. El-shatbyMoursy, Salma Moawad, Oleft Salem. Awareness, Knowledge and Practice of Breast selfexamination among groups of Female nursing students, Riyadh, Kingdom of Saudi Arabia. International Research Journal of Biological Sciences. 2014; 3(2):58-63.
39. Al-Naggar RA, Al-Naggar DH, Bobryshev YV, Chen R and Assabri A. Practice and barriers toward Breast Self-Examination among Young Malaysian Women. Asian Pacific Journal of Cancer Prevention. 2011; 12: 1173-78.

40. Stillman MJ. Women's health beliefs about breast cancer and breast self-examination. Nursing Research. 1997; 26: 121-127.

41. Gallup Organization, Inc. Women's attitudes regarding breast cancer. Occup Health Nurs. 1974; 20: 20-23.

42. Foster RS. Breast self-examination practices and breast cancer stage. N Engl J Med. 1978; 229: 265 270.

43. Sukhpal Kaur, Indarjit Walia. Knowledge and practices of breast self-examination among nursing students. Nursing and Midwifery Research Journal. 2007; 3 (3):128-137

44. Champion VL. The relationship of breast selfexamination to health belief model variables Research in Nursing and Health. 1987; 10: 375 382.

45. Rutledge DN, Duvis GT. Breats self-examination compliance and health belief model. Oncology Nursing Forum. 1988; 15: 175-79.

46. Budden L. Registered nurses' breast selfexamination practice and teaching to female clients. Journal of Community Health Nursing. 1998; 15: 101-112. 